\title{
Schedule-induced attack as a function of length of exposure to a fixed-time 90 -sec schedule
}

\author{
THOMAS A. LOONEY \\ Lynchburg College, Lynchburg, Virginia 24501 \\ and \\ L. DUANE DOVE \\ Winthrop College, Rock Hill, South Carolina 29730
}

\begin{abstract}
Twenty-four White King pigeons were exposed to a fixed-time (FT) 90-sec schedule of food presentation. For half of the subjects, a pictorial target was presented during the second session with the FT 90-sec schedule and throughout the remainder of the experiment. For the remaining subjects, the target was not made available until Session 26 with the FT 90-sec schedule. During early target availability, more subjects attacked in the late introduction condition. After extended exposure to the reinforcement schedule, however, similar numbers of subjects attacked in the two groups, eight in the early and nine in the late introduction group. The data suggest that when subjects are exposed only to a reinforcement schedule of moderate density, extended exposure with or without the target increases the probability that they will subquently attack the target.
\end{abstract}

Studies of schedule-induced attack in pigeons have used a variety of targets. Live restrained targets are generally attacked by all subjects; however, they are sometimes attacked so vigorously that the resultant damage (Azrin, Hutchinson, \& Hake, 1966; Cohen \& Looney, 1973) and target counterattack raises humane as well as practical considerations (Webbe, DeWeese, \& Malagodi, 1974). Attempts have been made to resolve these problems by rotating targets across sessions (Richards \& Rilling, 1972) or by using taxidermically stuffed pigeons (Azrin et al., 1966). Although these methods allow for continuation of experimental sessions, they do not preclude the possibility of damage to the target or the introduction of confounding variables in the form of uncontrolled target characteristics (Azrin et al., 1966; Knutson, 1973) or spuriously high attack rates from target movement and "bounce" (Flory \& Ellis, 1973). Alternative targets that have been used include a mirror (e.g., Cohen \& Looney, 1973; Dove, 1976; Moore, Tychsen, \& Thompson, 1976), a colored photograph (Looney, Cohen, \& Yoburn, 1976; Yoburn $\&$ Cohen, in press), and a rear-projected image of a pigeon (e.g., Looney et al., 1976; Looney \& Dove, in press). These two-dimensional targets eliminate most of the problems associated with the use of live and stuffed targets mentioned earlier. Moreover, studies that have employed pictorial targets (e.g., Looney \&

This research was supported in part by Biomedical Support Grant RR07143 from the Department of Health, Education, and Welfare. The authors thank M. A. Looney for her helpful comments. Reprints may be obtained from T. A. Looney, Department of Psychology, Lynchburg College, Lynchburg, Virginia 24501.
Cohen, 1974) have found that the temporal pattern, topography, and locus of attack on the target were comparable to that found with stuffed and live pigeons. However, conditions that generate attack against live targets sometimes have failed to produce attack upon pictorial targets by experimentally naive subjects.

The time of target presentation has been found to influence whether the two-dimensional target is readily attacked. Looney et al. (1976, Experiment 1) presented pigeons with a series of food schedules that were gradually changed from high-density schedules, fixed time (FT) $5 \mathrm{sec}$ or fixed ratio (FR) 1, to moderatedensity schedules, FT $90 \mathrm{sec}$ or FR 100 . The subjects for whom the target was present during the transition from high-density to moderate-density schedules showed little attack, but the subjects not exposed to the target until the terminal schedule was reached showed sustained attack. An interesting finding was that one subject who frequently attacked the target during a noschedule baseline condition showed sustained attack although the target was present during the leaning of the food schedule. A similar finding of baseline attack predicting later attack on a target presented during a dense schedule was noted in a second experiment by Looney et al. (1976) and by Ator (Note 1), who employed a mirror target. Ator also replicated the primary finding that subjects were more likely to attack the target if it was not presented until the schedule had been gradually leaned.

Given the studies by Looney et al. (1976) and Ator (Note 1), it appears that at least with some targets, exposure to the target during conditions that typically do not generate attack (i.e., extended no-schedule 
sessions and dense schedules) may decrease subsequent attack probability (cf. Galef, 1970; Scott, 1958). Another variable is suggested in a study by Looney and Cohen (1974), who found that extended exposure to reinforcement schedules in the absence of a target may increase the probability of a later schedule-induced attack.

The present study was designed to assess the importance of experience with a FT 90-sec schedule with or without a target present on subsequent attack. Pigeons were exposed to a rear-projected target in the presence of a FT 90-sec schedule that has been found to be effective in inducing attack. Half of the subjects were exposed to the target after only one session of the FT 90-sec schedule, while the remaining subjects were exposed to the target after 25 sessions of the schedule. If it is primarily length of exposure to an inducing schedule that is the important variable, then subjects in the late condition should show more initial attack, but once both groups have had extended exposure to the schedule, they should have similar numbers of attackers.

\section{METHOD}

\section{Subjects}

Twenty-four experimentally naive 1-year-old male White King pigeons from Palmetto Pigeon Plant (Sumter, South Carolina) were maintained at $75 \%( \pm 15 \mathrm{~g})$ of their free-feeding body weights. They were visually isolated from each other in individual home cages under $16 \mathrm{~h}$ of light followed by $8 \mathrm{~h}$ of darkness. Water and health grit were continuously available. Wing and tail feathers were kept short by periodic trimmings.

\section{Apparatus}

Two black operant pigeon chambers $(35.6 \times 35.6 \times 34.3 \mathrm{~cm}$ high) with black three-key intelligence panels were located in separate rooms. The keys were covered with black tape. The food hopper could be made available through a $5.0 \times 5.7 \mathrm{~cm}$ opening centered on the intelligence panel $8.9 \mathrm{~cm}$ above the floor.

The target image was provided by a rear-view projection unit described in detail by Cohen, Yoburn, and Looney (1976). The colored image of a conspecific was very similar in appearance to Pictorial Target $\mathrm{C}$ employed by Looney et al. (1976). It was projected onto a Polacoat plastic screen located behind an $11.4 \times 15.2 \mathrm{~cm}$ high opening centered on the rear wall $8.9 \mathrm{~cm}$ from the floor. To prevent damage to the screen and to eliminate reflections from it, the screen was covered with a piece of Con-Tact brand transparent self-adhesive plastic. An attack response was recorded when a force of at least $.2 \mathrm{~N}$ was applied to the target screen. The only chamber illumination was provided by the projected image. A blower provided ventilation and a white-noise generator masked extraneous sounds. Standard electromechanical control and recording devices were located in an adjacent room.

\section{Procedure}

All subjects were trained to eat reliably from the food hopper. This required either one or two sessions. The birds were then arbitrarily assigned to two groups which were matched for weight. All subjects were then exposed to a FT 90-sec food schedule. The first food presentation occurred with the introduction of the subject into the experimental chamber. Thereafter, food presentation was scheduled to occur after
90 sec. A protective contingency delayed food delivery until no attack had occurred for $10 \mathrm{sec}$. Sessions ended with the 11 th 10 -sec hopper presentation. The target was presented to the early group during Session 2 of the FT 90-sec schedule condition and to the late group during Session 26 of the FT $90 \mathrm{sec}$. Once the target was introduced, it remained in the chamber thereafter. Subjects in the early group were exposed to the FT 90-sec condition for a range of 20-40 sessions. They were then exposed to a no-food condition for 15-30 sessions, followed by a return to the FT 90-sec schedule for 25-30 sessions. During the no-food condition, subjects were placed in the chamber for $25 \mathrm{~min}$. Subjects in the late group were exposed to the FT 90-sec schedule in the presence of the target for 20-35 sessions, followed by $15-35$ no-food sessions, followed by a return to the FT 90 -sec schedule for $20-30$ sessions.

\section{RESULTS AND DISCUSSION}

Eight birds in the early group and nine in the late group engaged in sustained attack, a very similar number of attackers generated by each procedure. The groups did, however, differ in time of onset of attack. In the early group, one subject began attacking during the 1st session of target availability, four during the 2 nd, one during the 5 th, one during the 25 th, and one during the 30th. In the late group, seven birds began attacking during the 1st session of target availability, one during the $2 \mathrm{nd}$, and one during the $11 \mathrm{th}$. Comparisons of the adequacy of the two procedures for inducing attack should take into account the total number of FT 90-sec sessions, as well as the length of time the subjects must be exposed to the target in the presence of the FT 90-sec schedule. For example, during the first 15 sessions of target availability, the early condition had produced six attackers and the late condition had produced nine attackers. After the same total number of FT 90-sec sessions irrespective of target availability, however, the two conditions produced similar numbers of attackers. Hence, the data suggest that prolonged exposure to a FT 90-sec schedule can increase the probability of subsequent attack. Thus, contrary to Scott's (1958) theory of "passive inhibition," repeated failure to attack in a situation does not necessarily prevent subsequent attack in the same situation.

That is not to say, however, that the presence of a target during exposure to schedules with short interfood intervals prior to exposure to less dense schedules may not attentuate subsequent attack (Looney et al., 1976; Ator, Note 1). It should perhaps be noted that the two subjects that attacked after extended exposure to the target had the lowest response rates (approximately one and two attacks per minute, respectively) of any subjects in the early group. This may, however, not have been due to "learning not to attack," since two subjects in the late group had similar response rates.

In other regards, results from this study were similar to previous results with pictorial targets. There was a great deal of variability in response rates between subjects. Attack rates ranged from 1 to 40 responses 
per minute for 16 of the attackers, with the remaining attacker responding at approximately 75 responses per minute. This subject differed from the other attackers in that it continued to respond in the no-food condition at approximately the same rate as during the schedule condition (see Looney et al., 1976; Looney \& Dove, in press). As noted by Yoburn and Cohen (in press), several of the subjects initially had extended bouts of attack (thus encountering the protective contingency) before responding was confined to the period immediately after the food removal. The only subject that continued to respond throughout most of the interfood interval was the bird that responded 75 times per minute.

The results for the late group replicate almost exactly previous findings with a similar projected image (Looney et al., 1976). Recently, similar results have also been obtained in Flory's laboratory (Flory, Note 2). Using a projection system like the one employed in the present study and White King pigeons with extended exposure to intermittent reinforcement prior to target introduction, Flory and his colleagues found that seven of eight birds showed sustained attack of the target. The importance of the present study lies in the finding that a projected image is an adequate target for a relatively large percentage $(50 \%)$ of subjects in the early group soon after target introduction and for additional subjects after extended exposure (25-30 sessions) to the target.

\section{REFERENCE NOTES}

1. Ator, N. A. Interchangeability of mirror attack and response-produced timeout in pigeons. Paper presented at the meeting of the American Psychological Association, Washington, D.C., September 1976.

2. Flory, R. K. Personal communication, January 18, 1978.

\section{REFERENCES}

Azrin, N. H., Hutchinson, R. R., \& HAKe, D. F. Extinctioninduced aggression. Journal of the Experimental Analysis of Behavior, 1966, 9, 191-204.
Cohen, P. S., \& Looney, T. A. Schedule-induced mirror responding in the pigeon. Journal of the Experimental Analysis of Behavior, 1973, 19, 395-408.

Cohen, P. S., Yoburn, B. C., \& Looney, T. A. An inexpensive random-access projector for rapid presentation of pictorial images. Journal of the Experimental Analysis of Behavior, 1976, 26, 131-134.

Dove, L. D. The relationship between level of food deprivation and rate of schedule-induced aggression. Journal of the Experimental Analysis of Behavior, 1976, 25, 63-68.

FloRY, R. K., \& Ellis, B. B. Schedule-induced aggression against a slide-image target. Bulletin of the Psychonomic Society, 1973, 2, 287-290.

GALEF, B. G., JR. Target novelty elicits and directs shockassociated aggression in wild rats. Journal of Comparative and Physiological Psychology, 1970, 71, 87-91.

KnUtson, J. F. Aggression as manipulatable behavior. In J. F. Knutson (Ed.), The control of aggression. Chicago: Aldine, 1973.

Looney, T. A., \& CoHen, P. S. Pictorial target control of schedule-induced attack in White Carneaux pigeons. Journal of the Experimental Analysis of Behavior, 1974, 21, 571-584.

Looney, T. A., Cohen, P. S., \& Yoburn, B. C. Variables affecting establishment of schedule-induced attack on pictorial targets in White King pigeons. Journal of the Experimental Analysis of Behavior, 1976, 26, 349-360.

LOONEY, T. A., \& Dove, L. D. The effects of the presence of a home-chamber target on experimental-session attack. Physiology \& Behavior, in press.

Moore, M. S., Tychsen, R. L., \& Thompson, D. M. Extinction-induced mirror responding as a baseline for studying drug effects on aggression. Pharmacology Biochemistry \& Behavior, 1976, 4, 99-102.

Richards, R. W., \& Rilling, M. Aversive aspects of a fixed-interval schedule of food reinforcement. Journal of the Experimental Analysis of Behavior, 1972, 17, 405-411.

Scotr, J. P. Aggression. Chicago: University of Chicago Press, 1958.

Webbe, F. M., DeWeese, J., \& Malagodi, E. F. Induced attack during multiple fixed-ratio, variable-ratio schedules of reinforcement. Journal of the Experimental Analysis of Behavior, 1974, 22, 197-206.

Yoburn, B. C., \& Cohen, P. S. Assessment of attack and drinking in pigeons on time-dependent food schedules. Journal of the Experimental Analysis of Behavior, in press.

(Received for publication July 7, 1978.) 